\title{
Insulin resistance and adiponectin levels are associated with height catch-up growth in pre-pubertal Chinese individuals born small for gestational age
}

Hong-Zhu Deng ${ }^{1,2+}$, Hong Deng ${ }^{3+}$, Zhe Su${ }^{2}$, Yan-Hong Li $i^{2}$, Hua-Mei Ma ${ }^{2}$, Hong-Shan Chen ${ }^{2}$ and Min-Lian Du ${ }^{2 *}$

\begin{abstract}
s
Background and objective: The study was performed to determine whether catch-up growth is associated with the development of insulin resistance and to explore serum endocrine markers associated with the metabolism of adipose tissue in a Chinese population born small for gestational age(SGA)
\end{abstract}

Subjects and methods: We recruited 56 children born SGA with catch-up growth and 55 born without catch-up growth, who were further grouped into groups I (with BMI catch-up) and II (without BMI catch-up) respectively, as well as 52 children born appropriate for gestational age (AGA) with normal height. Their serum fasting insulin, fasting glucose, insulin-like growth factor-1, adiponectin, IGFBP-1, triglyceride concentrations, and the homeostasis assessment model for insulin resistance (HOMA-IR) were evaluated.

Results: (1) The HOMA-IR values in SGA-I with catch-up growth group were significantly higher than those in SGA-II with catch-up growth, SGA-I without catch-up growth and AGA children respectively. (2) The serum adiponectin levels of individuals in the SGA-I without catch-up growth and SGA-II with catch-up growth groups were significantly lower than those from the SGA-II without catch-up growth group. There was no difference in triglyceride or IGFBP-1 levels among the groups. (3) The degree of HOMA-IR was positively correlated with age, current $\mathrm{BMI}$ and $\triangle$ height SDS in SGA children.

Conclusion: The development of insulin resistance and lower levels of adiponectin were closely correlated with higher BMI and the postnatal height catch-up growth in SGA children.

Keywords: Small for gestational age, Catch-up growth, Insulin resistance, Adiponectin

\section{Introduction}

Epidemiological studies have suggested that children born small for gestational age (SGA) are at higher risk for developing metabolic syndromes in adulthood, including insulin resistance, type 2 diabetes, and cardiovascular diseases [1-3]. The "thrifty phenotype" hypothesis suggests that early life metabolic adaptations aid in the survival of an organism by selecting an appropriate growth trajectory in response to adverse intrauterine environmental cues [2].

\footnotetext{
* Correspondence: dhz1114@yahoo.cn

${ }^{\dagger}$ Equal contributors

2Department of Pediatrics, The First Affiliated Hospital of Sun Yat-sen University, Guangzhou, China

Full list of author information is available at the end of the article
}

Catch-up growth in postnatal development is very common in young children born SGA. Previous studies have shown that children born SGA with catch-up growth exhibit fat accumulation, abnormal development of adipose tissue and adipocyte function caused by adverse intrauterine growth, which contributes to the development of insulin resistance [4-7]. However, most of these previous studies did not discuss the contribution of height and fat catch-up growth to insulin resistance, though the strong association between low birth weight and insulin resistance has been described [8-10]. Hence, the discovery of the relative contribution of catch-up growth to the development of insulin resistance is of great importance for developing strategies to prevent insulin resistance-related

\section{Biomed Central}

(c) 2012 DENG et al.; licensee BioMed Central Ltd. This is an Open Access article distributed under the terms of the Creative Commons Attribution License (http://creativecommons.org/licenses/by/2.0), which permits unrestricted use, distribution, and reproduction in any medium, provided the original work is properly cited. 
metabolic syndromes, especially in the Chinese population. Adiponectin, IGFBP-1and triglycerides have been implicated in the pathophysiology of obesity-related insulin resistance, glucose intolerance, and insulin-mediated lipoprotein metabolism. Hypoadiponectinemia has been associated with insulin resistance in both animal and human studies. Only limited and controversial information is available about circulating adiponectin, IGFBP1and triglyceride levels in pre-pubertal children born SGA [11-13].

This study is a retrospective study aiming to determine whether children born SGA with catch-up growth are associated with the early development of insulin resistance in a Chinese population and investigating adiponectin, IGFBP-1and triglyceride levels in SGA children, while accounting for the height and fat catch-up growth.

\section{Subjects and methods}

A total of 111 children born SGA and 52 children born AGA were recruited from out-patient services at the Department of Pediatrics and Obstetrics of the First Affiliated Hospital, Sun Yat-Sen University for regular physical examination from Jan 2006 to Dec 2009. The SGA children were all follow-up cases born in our hospital, and they received regular physical examination once every one to three months. The maternal age of SGA groups was $(30 \pm 4)$ years. Multiple gestation (30/111, 27\%), gestational hypertension/pre-eclampsia (21/111, 19\%), pre-existing (before pregnancy) diabetes $(12 / 111,11 \%)$, gestational diabetes $(10 / 111,9 \%)$, intrahepatic cholestasis of pregnancy $(8 / 111,7 \%)$, maternal infection with syphilis or $\operatorname{HIV}(3 / 111,3 \%)$, maternal smoking or alcohol use or illicit drug use during pregnancy $(2 / 111,2 \%)$ were included in SGA groups.

All of the children with age range $3.5 y$ r to $10.2 \mathrm{yr}$ were born between 37 and 42 weeks of gestation, were nonobese (based on the standard deviation score (SDS) of body mass index $\leq 2$ for the chronological age and gender) and were in the pre-pubertal period defined as Tanner I. SGA was defined as a birth weight and length $<-2$ standard deviation (SD), and AGA was defined as individuals with a birth weight and length $\geq-2$ $\mathrm{SD}$ and $\leq 2 \mathrm{SD}$ for the gestational age, according to Chinese standards [9]. The SGA children were further divided into four groups (Table 1): (1) SGA-I with catchup growth $(n=40 ; 23 \mathrm{~F}, 17 \mathrm{M})$, (2) SGA-II with catch-up growth $(n=16 ; 7 \mathrm{~F}, 9 \mathrm{M})$, (3) SGA-I without catch-up growth $(n=37 ; 16 \mathrm{~F}, 21 \mathrm{M})$, and (4) SGA-II without catchup growth $(n=18 ; 8 \mathrm{~F}, 10 \mathrm{M})$. Children born SGA without catch-up growth had serum maximum growth hormone (GH) levels of greater than $10 \mu \mathrm{g} / \mathrm{L}$ (results from $\mathrm{GH}$ provocative tests using Levodopa and Pyridostigmine). GH therapy was not administered to all of the SGA Children during the follow-up period. The AGA group of children ( $n=52 ; 23 \mathrm{~F}, 29 \mathrm{M})$ with normal height and weight were matched according to age, gender and Tanner stage in the SGA groups.

Individual subjects who had chromosome abnormalities, congenital skeletal deformations, hypothyroidism, congenital malformation-related growth retardation, chronic diseases, or long-term medication were excluded. Children, with first-degree relatives who suffered from type 2 diabetes and metabolic syndrome, or who were born from mothers with gestational diabetes, were excluded. Obese children were also excluded to avoid another confounding factor in our study.

Informed consent was obtained from their parents, and the experimental 1 protocol was approved by the Local Ethics Committee.

\section{Measurements}

An individual's birth length and weight were obtained from hospital records and their target heights were calculated as mid-parental height minus $6.5 \mathrm{~cm}$ for girls and mid-parental height plus $6.5 \mathrm{~cm}$ for boys. Their current height, weight, and body mass index (BMI) were also measured. Age- and gender-adjusted SDS for height, weight, and BMI were calculated using reference tables of Chinese children $[14,15]$. The SDScorrected height for individual subjects was calculated using the actual height SDS minus target height SDS. The $\Delta$ height SDS was calculated using the current height SDScorrected minus birth length SDS, while the ${ }^{\Delta}$ weight SDS was determined using the current weight SDS minus birth weight SDS. The BMI of individual children was calculated as weight $(\mathrm{kg}) /$ height $(\mathrm{m})^{2}$. The $\triangle$ BMI SDS was determined using the current BMI SDS minus birth BMI SDS. The demographic characteristics and measured values are listed in Table 2.

Table 1 Grouping criteria for the SGA and AGA groups

\begin{tabular}{|c|c|}
\hline (1) SGA-I with catch-up growth $(n=40 ; 23 F, 17 M)$ & Birth length SDS $<-2$, Height $\mathrm{SDS}_{\text {Corrected }}>-2$ and $\triangle \mathrm{BMI} \mathrm{SDS}>0$ \\
\hline (2)SGA-II with catch-up growth ( $n=16 ; 7 F, 9 M)$ & Birth length SDS $<-2$, Height $\mathrm{SDS}_{\text {Corrected }}>-2$ and $\triangle \mathrm{BMI} \mathrm{SDS} \leq 0$ \\
\hline (3)SGA-I without catch-up growth $(n=37 ; 16 \mathrm{~F}, 21 \mathrm{M})$ & Birth length SDS $<-2$, Height $\mathrm{SDS}_{\text {Corrected }} \leq-2$ and $\Delta$ Height SDS $\leq 0$ and $\Delta \mathrm{BMI}$ SDS $>0$ \\
\hline (4)SGA-II without catch-up growth ( $n=18 ; 8 \mathrm{~F}, 10 \mathrm{M})$ & Birth length SDS $<-2$, Height $\mathrm{SDS}_{\text {Corrected }} \leq-2$ and $\Delta$ Height $\mathrm{SDS} \leq 0$ and $\triangle \mathrm{BMI} S \mathrm{SDS} \leq 0$ \\
\hline (5)AGA $(n=52 ; 23 \mathrm{~F}, 29 \mathrm{M})$ & Birth length SDS $\geq-2$ and $\leq 2$, Height $\mathrm{SDS}_{\text {Corrected }}>-2$ \\
\hline
\end{tabular}

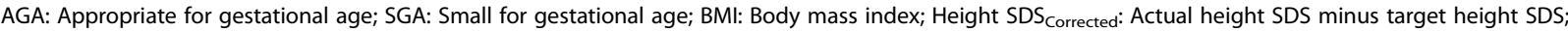
$\triangle$ Height SDS: Current height SDS corrected minus birth length SDS; $\triangle$ BMI SDS: Current BMI SDS minus birth BMI SDS. 
Table 2 Clinical and anthropometric parameters of SGA and AGA children at birth and investigation

\begin{tabular}{|c|c|c|c|c|c|}
\hline & $\begin{array}{l}\text { SGA-I with catch-up } \\
\text { growth }\end{array}$ & $\begin{array}{l}\text { SGA-II with catch-up } \\
\text { growth }\end{array}$ & $\begin{array}{l}\text { SGA-I without catch-up } \\
\text { growth }\end{array}$ & $\begin{array}{l}\text { SGA-II without catch-up } \\
\text { growth }\end{array}$ & AGA \\
\hline & $n=40$ & $n=16$ & $n=37$ & $n=18$ & $n=52$ \\
\hline Gender(M:F) & $17: 23$ & $9: 7$ & $21: 16$ & $10: 8$ & $29: 23$ \\
\hline $\begin{array}{l}\text { Midparental height } \\
(\mathrm{cm})\end{array}$ & $161.38 \pm 0.80$ & $162.27 \pm 0.45$ & $162.75 \pm 0.54$ & $162.00 \pm 0.73$ & $160.14 \pm 0.44$ \\
\hline Age(year) & $6.78 \pm 0.88$ & $6.27 \pm 0.96$ & $5.30 \pm 0.67$ & $5.91 \pm 0.98$ & $7.14 \pm 0.39$ \\
\hline $\begin{array}{l}\text { Gestational age } \\
\text { (weeks) }\end{array}$ & $38.76 \pm 0.21$ & $39.17 \pm 0.19$ & $38.76 \pm 0.21$ & $39.17 \pm 0.19$ & $39.23 \pm 0.14$ \\
\hline Birth weight SDS & $-2.27 \pm 0.18^{*}$ & $-1.82 \pm 0.39^{*}$ & $-2.61 \pm 0.11^{*}$ & $-1.83 \pm 0.25^{*}$ & $0.23 \pm 0.04$ \\
\hline Birth length SDS & $-2.42 \pm 0.14^{*}$ & $-3.00 \pm 0.25^{*}$ & $-2.02 \pm 0.21^{*}$ & $-2.29 \pm 0.19^{*}$ & $0.14 \pm 0.03$ \\
\hline Birth BMI SDS & $-1.51 \pm 0.37^{*}$ & $-1.29 \pm 0.45^{*}$ & $-1.91 \pm 0.45^{*}$ & $-1.47 \pm 0.38^{*}$ & $0.39 \pm 0.24$ \\
\hline Weight SDS & $-1.65 \pm 0.41$ & $-2.18 \pm 0.53$ & $-2.11 \pm 0.37$ & $-4.02 \pm 0.57^{*}$ & $-1.41 \pm 0.25$ \\
\hline Height SDS Corrected & $-0.93 \pm 0.22$ & $-1.49 \pm 0.15$ & $-3.24 \pm 0.18^{*}$ & $-2.82 \pm 0.29^{*}$ & $-1.05 \pm 0.07$ \\
\hline BMI SDS & $-0.15 \pm 0.19^{\#}$ & $-1.18 \pm 0.19$ & $-0.76 \pm 0.25$ \# & $-1.63 \pm 0.25^{*}$ & $-0.32 \pm 0.12$ \\
\hline $\begin{array}{l}\Delta \text { Height SDS } \\
\text {. }\end{array}$ & $1.57 \pm 0.27^{*}$ & $1.51 \pm 0.21^{*}$ & $-1.24 \pm 0.26$ & $-1.21 \pm 0.23$ & $-0.73 \pm 0.28$ \\
\hline$\Delta$ Weight SDS & $0.63 \pm 0.39^{*} \#$ & $-0.36 \pm 0.34$ & $0.50 \pm 0.35^{*} \#$ & $-2.19 \pm 0.46$ & $-1.52 \pm 0.37$ \\
\hline$\triangle \mathrm{BMI} S D S$ & $1.36 \pm 0.47^{*}$ \# & $-0.06 \pm 0.35$ & $1.33 \pm 0.36^{*} \#$ & $-0.17 \pm 0.34$ & $-0.71 \pm 0.25$ \\
\hline
\end{tabular}

${ }^{*} \mathrm{P}<0.05 \mathrm{SGA}-\mathrm{I}$ or SGA-II vs AGA; $\mathrm{P}<0.05 \mathrm{SGA}-\mathrm{I}$ vs SGA-II.

AGA: Appropriate for gestational age; SGA: Small for gestational age; BMI: Body mass index; $\triangle$ Height SDS: Current height SDS corrected minus birth length SDS;

$\triangle$ Weight SDS: Current Weight SDS minus birth Weight SDS; $\triangle$ BMI SDS: Current BMI SDS minus birth BMI SDS.

\section{Laboratory examinations}

After overnight fasting, blood samples were collected and sera were prepared by centrifugation and stored at $-70^{\circ} \mathrm{C}$. The serum glucose concentrations were analysed immediately. The concentration of serum insulin and IGF-I for individual subjects were simultaneously determined via routine laboratory examinations. The concentration of blood glucose was determined using the hyperoxidase method (Photometric Instrument 4010; Roche, Basel, Switzerland). The intra-assay coefficient of variation of this method was $<2.0 \%$. The serum insulin concentrations were determined via radioimmunoassay (RIA) using the insulin RIA kit, according to the manufacturer's instructions (Phadeseph Insulin RIA, Pharmacia \&Upjohn Diagnostics AB, Uppsala, Sweden). The intra- and interassay coefficients of variation were $5.3 \%$ and $7.6 \%$, respectively. The serum IGF-I concentrations were determined using an ELISA kit, according to the manufacturer's instructions (Diagnostic Systems Laboratories -10-2800, Inc., Webster, TX, USA). The sensitivity of the assay was $0.01 \mathrm{ng} / \mathrm{mL}$. The inter- and intra-assay coefficients of variation were $3.3-6.8 \%$ and $4.5-8.6 \%$, respectively. The HOMA-IR was calculated as insulin (microunits per millilitre) $\times$ glucose (millimoles per litre) /22.5 and was used to evaluate IR in individual children [16].

\section{Statistical analyses}

Data were analysed using the Statistical Package for Social Sciences (SPSS, version 13.0 SPSS Inc, Chicago, IL, USA). Data for HOMA-IR were transformed into normal distributions by calculating the natural logarithms and were expressed as the geometric mean \pm standard error of mean (SEM). All other values were expressed as the arithmetic mean \pm SEM. Comparisons among the groups were performed using parametric tests. The differences among groups were assessed by one-way ANOVA and univariate analysis using Fisher's protected least significant difference test for inter-group comparisons. The differences between two groups were determined using unpaired $t$ tests. Differences in gender distribution between groups were assessed by $\chi 2$-tests. Relationships between variables were analysed by simple correlation (Pearson's test) and general linear models. A value of $P<0.05$ was considered statistically significant.

\section{Results}

\section{Anthropometry}

There was no difference in gender, age, or gestational age among these groups. As expected, birth weights and lengths SDS were significantly lower in SGA children than in AGA children. The values of height SDS $_{\text {corrected }}$ in SGA children without catch-up growth were lower than those of SGA with catch-up growth and AGA children $(P<0.001)$. Moreover the values of BMI SDS in SGA-I with and without catch-up growth children were higher than those of SGA-II with and without catch-up growth children respectively $(P<0.001)$. Furthermore, the values of BMI SDS in SGA-II without catch-up growth children were lower than in AGA children $(P=0.001)$, but there were no significant difference compared to the children in the SGA-II with catch-up growth group $(P=0.073)$. There was no difference in BMI SDS among 
the SGA-I with and without catch-up growth and AGA groups $(P>0.05$, Table 2$)$.

\section{Laboratory profile}

There was no significant difference in the concentration of fasting serum glucose among the groups of children. The HOMA-IR values in SGA-I children with catch-up growth were significantly higher than in SGA-II with catchup growth, SGA-I without catch-up growth and AGA children. These differences persisted despite adjusting for gender, age, and BMI ( $P=0.022,0.015,0.029$, respectively). The HOMA-IR values in two SGA groups without catchup growth were all comparable to the values in AGA children $(P>0.05)$.

The levels of adiponectin in the SGA-II with catch-up growth and SGA-I without catch-up growth groups were significantly lower than those in the SGA-II without catch-up growth group respectively $(P=0.008,0.011$, respectively). These differences appeared despite adjusting for BMI ( $P=0.038,0.035$, respectively). However, there was no significant difference when compared to the AGA group. There was no significant difference in the IGFBP-1and TG values among those groups even after adjusting for BMI $(P>0.05)$ (Table 3$)$.

\section{Correlation analysis}

Correlation analysis indicated that the HOMA-IR values were positively correlated with age $(r=0.375, P=0.003), \triangle \mathrm{Ht}$ $\operatorname{SDS}(r=0.431, P=0.000)$ and BMI $(r=0.417, P=0.001)$, however, they were not associated with birth weight $(P>0.05)$.

The HOMA-IR values were negatively correlated with the adiponectin and IGFBP-1 levels $(r=-0.33, P=0.03$; $r=-0.43, P<0.01)$ in the SGA group, but no correlation was observed with the levels of triglycerides. Adiponectin and IGFBP-1 levels exhibited a negative correlation with chronological age $(r=-0.427, P=0.001 ; r=-0.289$, $P=0.023$ ).

\section{Discussion}

In our study, SGA children, who had made a height catchup growth accompanied by a BMI catch-up growth, had significantly higher values of insulin resistance index compared to AGA children. This finding showed that the development of insulin resistance was associated with height and BMI catch-up growth in SGA children, which increased with age. These data were not in complete accordance with several previous reports $[9,17,18]$. The majority of previous studies did not analyse the contribution of BMI catch-up growth to insulin resistance during postnatal catch-up growth, though the strong association between low birth weight and insulin resistance has been described $[9,17,19]$. In our study population, $\triangle$ BMI SDS values were higher in SGA children than in AGA children. Because the high degree of BMI usually reflects the excess accumulation of fat in the body, our data suggest that there was body fat accumulation in SGA children, especially with catch-up growth in height during childhood and that the excess fat contributes to the development of insulin resistance in SGA children. SGA children with higher current BMI were more insulin-resistant than AGA children, in spite of their similar weight and BMI. The data also suggested that insulin resistance may precede the development of obesity. Other studies have suggested that low birth weight is a risk factor for the later development of abdominal or truncal obesity, and SGA children with catch-up weight gain show a dramatic transition toward central adiposity, which enhances insulin resistance [20-23]. Accordingly, the measures used to control overweight when gaining linear catch-up growth in childhood seem to be important in the prevention of insulin resistance in SGA children. Our findings indicated that height catch-up growth was an important influential factor for insulin resistance in SGA children. Our work might contribute to understanding the involvement of catch-up growth in the pathogenesis of insulin resistance in SGA groups.

Table 3 Laboratory profile of SGA and AGA children at investigation

\begin{tabular}{|c|c|c|c|c|c|}
\hline & $\begin{array}{l}\text { SGA-I with catch-up } \\
\text { growth }\end{array}$ & $\begin{array}{l}\text { SGA-II with catch-up } \\
\text { growth }\end{array}$ & $\begin{array}{l}\text { SGA-I without catch-up } \\
\text { growth }\end{array}$ & $\begin{array}{l}\text { SGA-II without catch-up } \\
\text { growth }\end{array}$ & AGA \\
\hline & $n=40$ & $n=16$ & $n=37$ & $n=18$ & $n=52$ \\
\hline $\begin{array}{l}\text { Fasting glucose } \\
(\mathrm{mmol} / \mathrm{L})\end{array}$ & $4.55 \pm 0.13$ & $4.68 \pm 0.14$ & $4.33 \pm 0.16$ & $4.66 \pm 0.18$ & $4.73 \pm 0.07$ \\
\hline $\begin{array}{l}\text { Fasting insulin(uU/ } \\
\mathrm{mL})\end{array}$ & $11.25 \pm 3.41^{*} \# \boldsymbol{\Lambda}$ & $5.10 \pm 0.64$ & $3.94 \pm 0.67$ & $3.10 \pm 0.66$ & $5.39 \pm 0.40$ \\
\hline HOMA-IR & $2.30 \pm 0.71^{*} \# \boldsymbol{\Lambda}$ & $1.04 \pm 0.11$ & $0.81 \pm 0.15$ & $0.65 \pm 0.14$ & $1.15 \pm 0.09$ \\
\hline Triglyceride (mmol/L) & $0.96 \pm 0.13$ & $1.03 \pm 0.18$ & $1.10 \pm 0.12$ & $0.85 \pm 0.14$ & $0.86 \pm 0.04$ \\
\hline Adiponectin(ug/mL) & $0.07 \pm 0.01$ & $0.09 \pm 0.02$ & $0.09 \pm 0.01$ & $0.15 \pm 0.07^{*} \# \boldsymbol{\Lambda}$ & $0.09 \pm 0.01$ \\
\hline IGFBP-1(ng/mL) & $111.08 \pm 8.75$ & $103.85 \pm 15.25$ & $90.18 \pm 12.74$ & $123.44 \pm 21.15$ & $106.54 \pm 11.96$ \\
\hline IGF-1(ng/mL) & $215.47 \pm 19.99$ & $206.56 \pm 37.77$ & $126.56 \pm 16.35 \boldsymbol{\Delta}$ & $171.11 \pm 31.32$ & $175.53 \pm 13.69$ \\
\hline
\end{tabular}

${ }^{*} \mathrm{P}<0.05 \mathrm{SGA}-\mathrm{I}$ or SGA-II vs AGA; $\mathrm{P}<0.05$ SGA-I vs SGA-II; $\Delta \mathrm{P}<0.05$ SGA-I with catch-up growth vs SGA-I without catch-up growth; SGA-II with catch-up growth vs SGA-II without catch-up growth.

AGA: Appropriate for gestational age; SGA: Small for gestational age; HOMA: Homeostasis assessment model; IR: Insulin resistance; IGF-1: Insulin-like growth factor1; IGFBP-1: Insulin-like growth factor binding protein-1. 
The implications of our results in relation to catch-up in height might be of potential importance when considering $\mathrm{GH}$ treatment.

Decreased adiponectin and IGFBP-1 levels and increased triglyceride levels are considered to reflect impaired insulin sensitivity and predict insulin resistance. Data on adiponectin, IGFBP-1 and triglyceride levels in SGA children in the literature have varied [24-27]. Adiponectin is one of the adipokines produced exclusively by adipocytes. Adiponectin knockout mice develop glucose intolerance, insulin resistance, and hyperlipidemia, especially when fed high-fat diets [28]. Decreased levels of plasma adiponectin have been found to be related to obesity, type 2 diabetes, and cardiovascular disease. Cianfarani et al. reported that the serum adiponectin levels were lower in SGA children (aged 8.6 $\pm 3.5 \mathrm{yr}$ ) than in short-normal children born AGA [29]. These differences were not observed in the research of Lopez-Bermejo et al. whose extensive analysis revealed that the group of overweight SGA children had lower serum adiponectin concentrations than lean SGA children [30]. Research on preterm infants had shown that the change in the serum adiponectin levels closely correlated to gains in body weight in AGA and SGA children [31]. One important finding of the present study was that adiponectin was not only associated with BMI catch-up, but also with linear catch-up growth in pre-pubertal SGA children. Our study also showed that adiponectin was inversely associated with insulin resistance markers. The results highlight that BMI and linear catch-up might be two independent determinants of hypoadiponectinemia in SGA children. Previous studies have shown that low birth weight followed by catch-up in body fat, especially visceral fat during childhood, even within the normal weight range, was associated with a higher risk of developing insulin resistance $[20,22]$. Our study also showed that the decreased adiponectin levels were associated with postnatal body fat accumulation in SGA children and added new information on this association because it showed the relevant role of fat and height catch-up. To the best of our knowledge, the relationship between linear catch-up and adiponectin are novel and may contribute to understanding the involvement of adiponectin in the pathogenesis of insulin resistance in SGA children.

IGFBP-1, produced in the liver, is suppressed by insulin through binding to insulin-response elements in the IGFBP-1 gene promoter, which forms a link between glucose metabolism and IGF axis [32]. Insulin resistance and impaired glucose tolerance are observed in IGFBP-1 transgenic mice [33]. Reduced serum IGFBP-1 levels are considered to reflect hyperinsulinemia and cardiovascular risk in adults and obese children [32,34]. Kamoda T et al. reported that the levels of serum IGFBP-1 were similar in short children born SGA and AGA [35]. Kistner A et al. investigated the serum markers of insulin resistance in adults born SGA and reported that lower IGFBP-1 and triglyceride levels were observed in the SGA group compared to the AGA group despite with normal BMI [36]. In our study, there were no marked differences in IGFBP-1 and triglyceride levels between SGA children with height and BMI catchup growth and their age-matched controls. In SGA children, especially non-catch-up growth subjects, the lower BMI may have influenced IGFBP-1and triglyceride levels, although we had adjusted for BMI. Further analysis showed that IGFBP-1 correlated significantly with the HOMA-IR. values. These differences and correlations were not observed with triglyceride levels. In this instance, our results were similar to the results published by Evagelidou EN et al., who reported that SGA children, although more insulin-resistant, had similar triglyceride levels to AGA children in pre-puberty [37]. Our findings indicated that adiponectin might be a more effective marker than IGFBP-1 and triglyceride for monitoring insulin resistance in SGA children with catch-up growth. However, these three markers were not sensitive enough at this age stage in non-obese SGA children.

We need to be aware of the limitations in interpreting the results of this study. The major limitation of the present study is the relatively small sample size. Another limitation is that the study design was based on retrospective data collecting. The third limitation is that both body fat and insulin resistance were studied using surrogate variables. These limitations might suggest that the results are not easily applicable to the whole population of pre-pubertal SGA children. However, we have presented the presence of four different SGA populations compared to normal controls in the exploration of system-wide adiponectin, IGFBP-1, triglyceride levels and insulin resistance in SGA children, while considering height and fat catch-up growth.

In conclusion, our study showed that children born SGA with catch-up growth for height and BMI are more insulin-resistant than children born AGA. Our study indicated that interventions to control overweight development in childhood seem to be important for preventing insulin resistance. Furthermore, lower levels of adiponectin were closely correlated with height and BMI catch-up growth in SGA children. Adiponectin may be a more useful marker than IGFBP-1 and triglyceride for monitoring insulin resistance in SGA children with catch-up growth.

\section{Abbreviations}

AGA: Appropriate for gestational age; SGA: Small for gestational age; BMI: Body mass index; SD: Standard deviation; SDS: Standard deviation score(s); IGF-1: Insulin-like growth factor-1; GH: Growth hormone; HOMA: Homeostasis assessment model; IR: Insulin resistance; IGFBP-1: Insulin-like growth factor binding protein-1.

\section{Competing interests}

The authors have nothing to disclose. 


\section{Authors' contributions}

HZD participated in the study design, execution and analysis, and also drafted the manuscript. HD participated in the execution, data analysis and interpretation of the study, and contributed to manuscript preparation. ZS participated in collection cases. YHL participated in collection cases. HMM participated in collection cases. HSC participated in collection cases. MLD participated in study design and data analysis, and contributed to manuscript preparation. All authors read and approved the final manuscript.

\section{Acknowledgements}

The study was supported by the Natural Science Foundation of China (Grant Number 81100571) and the Natural Science Foundation of Guangdong Province (Grant Number S2011020005224). The authors thank Professor Ke Han, PhD for his expert advice in statistical analysis.

\section{Grant support}

The Natural Science Foundation of China (Grant Number 81100571); The Natural Science Foundation of Guangdong Province (Grant Number S2011020005224).

\section{Author details}

'Department of Pediatrics, The Third Affiliated Hospital of Sun Yat-sen University, Guangzhou, China. ${ }^{2}$ Department of Pediatrics, The First Affiliated Hospital of Sun Yat-sen University, Guangzhou, China. ${ }^{3}$ Department of Infectious Diseases, The Third Affiliated Hospital of Sun Yat-sen University, Guangzhou, China.

Received: 20 August 2012 Accepted: 20 November 2012 Published: 28 November 2012

\section{References}

1. Varvarigou AA: Intrauterine growth restriction as a potential risk factor for disease onset in adulthood. J Pediatr Endocrinol Metab 2010, 23:215-224.

2. Hofman PL, Cutfield WS, Robinson EM, Bergman RN, Menon RK, Sperling MA, Gluckman PD: Insulin resistance in short children with intrauterine growth retardation. J Clin Endocrinol Metab 1997, 82:402-406.

3. Rotteveel J, van Weissenbruch MM, Twisk JW, Delemarre-Van de Waal HA: Infant and childhood growth patterns, insulin sensitivity, and blood pressure in prematurely born young adults. Pediatrics 2008, 122:313-321.

4. Fabricius-Bjerre S, Jensen RB, Færch K, Larsen T, Mølgaard C, Michaelsen KF Vaag A, Greisen G: Impact of birth weight and early infant weight gain on insulin resistance and associated cardiovascular risk factors in adolescence. PLoS One 2011, 6:e20595.

5. Maiorana A, Del Bianco C, Cianfarani S: Adipose tissue: a metabolic regulator Potential implications for the metabolic outcome of subjects born small for gestational age (SGA). Rev Diabet Stud 2007, 4:134-146.

6. Ong KK, Ahmed ML, Emmett PM, Preece MA, Dunger DB: Association between postnatal catch-up growth and obesity in childhood: prospective cohort study. BMJ 2000, 320:967-971.

7. Jaquet D, Deghmoun S, Chevenne D, Collin D, Czernichow P, Lévy-Marchal C Dynamic change in adiposity from fetal to postnatal life is involved in the metabolic syndrome associated with reduced fetal growth. Diabetologia 2005, 48:849-855.

8. Dallar Y, Dilli D, Bostanci I, Oğüş E, Doğankoç S, Tuğ E: Insulin sensitivity obtained from the oral glucose tolerance test and its relationship with birthweight. Ann Saudi Med 2007, 27:13-17.

9. Veening MA, Van Weissenbruch MM, Delemarre-Van De Waal HA: Glucose tolerance, insulin sensitivity, and insulin secretion in children born smal for gestational age. J Clin Endocrinol Metab 2002, 87:4657-4661.

10. Veening MA, van Weissenbruch MM, Heine RJ, Delemarre-van de Waal HA: Beta-cell capacity and insulin sensitivity in prepubertal children born small for gestational age: influence of body size during childhood. Diabetes 2003, 52:1756-1760.

11. Lihn AS, Pederson SB, Richeksen B: Adiponectin: action, regulation and association to insulin sensitivity. Obes Rev 2005, 6:13-21.

12. Mogul HR, Marshall M, Frey M, Burke HB, Wynn PS, Wilker S, Southern AL, Gambert SR: Insulin like growth factor-binding protein-1 as a marker for hyperinsulinaemia in obese menopausal women. J Clin Endocrinol Metab 1996, 81:4492-4495.
13. Jones JN, Gercel-Taylor C, Taylor DD: Altered cord serum lipid levels associated with small for gestational age infants. Obstet Gynecol 1999, 93:527-531

14. Zhang BL, Feng ZK, Zhang LH: Birth size standards by gestational age for Chinese neonates. Zhonghua Er Ke Za Zhi 1988, 26:206-208. in Chinese.

15. Hu YM, Jiang ZF: Growth development standards for Chinese children. In Zhu FuTang practical pediatr. 7th edition. BeiJing: The People Health press; 2002:27-34. in Chinese

16. Matthews DR, Hosker JP, Rudenski AS, Naylor BA, Treacher DF, Turner RC: Homeostasis model assessment: insulin resistance and $\beta$-cell function from fasting plasma glucose and insulin concentrations in man. Diabetologia 1985, 28:412-419.

17. Soto N, Bazaes RA, Peña V, Salazar T, Avila A, Iñiguez G, Ong KK, Dunger DB, Mericg MV: Insulin sensitivity and secretion are related to catch-up growth in small-for- gestational-age infants at age 1 year: results from a prospective cohort. J Clin Endocrinol Metab 2003, 88:3645-3650.

18. Deng HZ, Li YH, Su Z, Ma HM, Huang YF, Chen HS, Du ML: Association between height and weight catch-up growth with insulin resistance in pre-pubertal Chinese children born small for gestational age at two different ages. Eur J Pediatr 2011, 170:75-80

19. Iñiguez $G$, Ong $K$, Bazaes $R$, Avila A, Salazar T, Dunger D, Mericq V: Longitudinal changes in insulin-like growth factor-1, insulin sensitivity, and secretion from birth to age three years in small-for-gestational-age children. J Clin Endocrinol Metab 2006, 91:4645-4649.

20. Dulloo AG: Regulation of fat storage via suppressed thermogenesis: a thrifty phenotype that predisposes individuals with catch-up growth to insulin resistance and obesity. Horm Res 2006, 65:90-97.

21. Ibáñez L, Ong K, Dunger DB, de Zegher F: Early development of adiposity and insulin resistance after catch-up weight gain in small-forgestational-age children. J Clin Endocrinol Metab 2006, 91:2153-2158.

22. Ibáñez L, Suárez L, Lopez-Bermejo A, Díaz M, Valls C, de Zegher F: Early development of visceral fat excess following spontaneous catch-up growth in children with low birthweight. J Clin Endocrinol Metab 2008, 93:925-928.

23. Leunissen RW, Oosterbeek P, Hol LK, Hellingman AA, Stijnen T, Hokken-Koelega AC: Fat mass accumulation during childhood determines insulin sensitivity in early adulthood. J Clin Endocrinol Metab 2008, 93:445-451.

24. Sancakli O, Darendeliler F, Bas F, Gokcay G, Disci R, Aki S, Eskiyurt N: Insulin, adiponectin, IGFBP-1 levels and body composition in small for gestational age born non-obese children during prepubertal ages. Clin Endocrinol (Oxf) 2008, 69:88-92.

25. Ibáñez L, Lopez-Bermejo A, Diaz M, de Zegher F: Catch-up growth in girls born small for gestational age precedes childhood progression to high adiposity. Fertil Steril 2011, 96:220-223.

26. Miras M, Ochetti M, Martín S, Silvano L, Sobrero G, Castro L, Onassis M, Tolosa de Talamoni N, Pérez A, Picotto G, Díaz de Barboza G, Muñoz L: Serum levels of adiponectin and leptin in children born small for gestational age: relation to insulin sensitivity parameters. $J$ Pediatr Endocrinol Metab 2010, 23:463-471.

27. Challa AS, Evagelidou EN, Cholevas VI, Kiortsis DN, Giapros VI, Drougia AA, Andronikou SK: Growth factors and adipocytokines in pre-pubertal children born small-for-gestational age: relation to insulin resistance. Diabetes Care 2009, 32:714-719.

28. Blackburn GL: From bench to bedside: novel mechanisms and therapeutic advances through the development of selective peroxisome proliferator-activated receptor c modulators. Am J Clin Nutr 2010, 91:251S-253S.

29. Cianfarani S, Martinez C, Maiorana A, Scirè G, Spadoni GL, Boemi S: Adiponectin levels are reduced in children born small for gestational age and are inversely related to postnatal catch-up growth. J Clin Endocrinol Metab 2004, 89:1346-1351.

30. López-Bermejo A, Casano-Sancho P, Fernández-Real JM, Kihara S, Funahashi T Rodríguez-Hierro F, Ricart W, Ibañez L: Both intrauterine growth restriction and postnatal growth influence childhood serum concentrations of adiponectin. Clin Endocrinol (Oxf) 2004, 61:339-346.

31. Saito $M$, Nishimura $K$, Nozue $H$, Miyazono $Y$, Kamoda $T$ : Changes in serum adiponectin levels from birth to term-equivalent age are associated with postnatal weight gain in preterm infants. Neonatology 2011, 100:93-98.

32. van der Kaay D, Deal C, de Kort S, Willemsen R, Leunissen R, Ester W, Paquette J, van Doorn J, Hokken-Koelega A: Insulin-like growth factorbinding protein-1: serum levels, promoter polymorphism, and 
associations with components of the metabolic syndrome in short subjects born small for gestational age. J Clin Endocrinol Metab 2009, 94:1386-1392.

33. Murphy LJ: Over expression of insulin-like growth factor binding protein1 in transgenic mice. Pediatr Nephrol 2000, 14:567-571.

34. Gokulakrishnan K, Velmurugan K, Ganesan S, Mohan V: Circulating levels of insulin-like growth factor binding protein-1 in relation to insulin resistance, type 2 diabetes mellitus, and metabolic syndrome (Chennai Urban Rural Epidemiology Study 118). Metabolism 2012, 61:43-46.

35. Kamoda T, Nozue H, Matsui A: Serum levels of adiponectin and IGFBP-1 in short children born small for gestational age. Clin Endocrinol (Oxf) 2007, 66:290-294.

36. Kistner A, Jacobson SH, Celsi G, Vanpee M, Brismar K: IGFBP-1 levels in adult women born small for gestational age suggest insulin resistance in spite of normal BMI. J Intern Med 2004, 255:82-88.

37. Evagelidou EN, Giapros VI, Challa AS, Kiortsis DN, Tsatsoulis AA, Andronikou SK: Serum adiponectin levels, insulin resistance, and lipid profile in children born small for gestational age are affected by the severity of growth retardation at birth. Eur J Endocrinol 2007, 156:271-277.

doi:10.1186/1743-7075-9-107

Cite this article as: Deng et al:: Insulin resistance and adiponectin levels are associated with height catch-up growth in pre-pubertal Chinese individuals born small for gestational age. Nutrition \& Metabolism 2012 9:107.

\section{Submit your next manuscript to BioMed Central and take full advantage of:}

- Convenient online submission

- Thorough peer review

- No space constraints or color figure charges

- Immediate publication on acceptance

- Inclusion in PubMed, CAS, Scopus and Google Scholar

- Research which is freely available for redistribution 